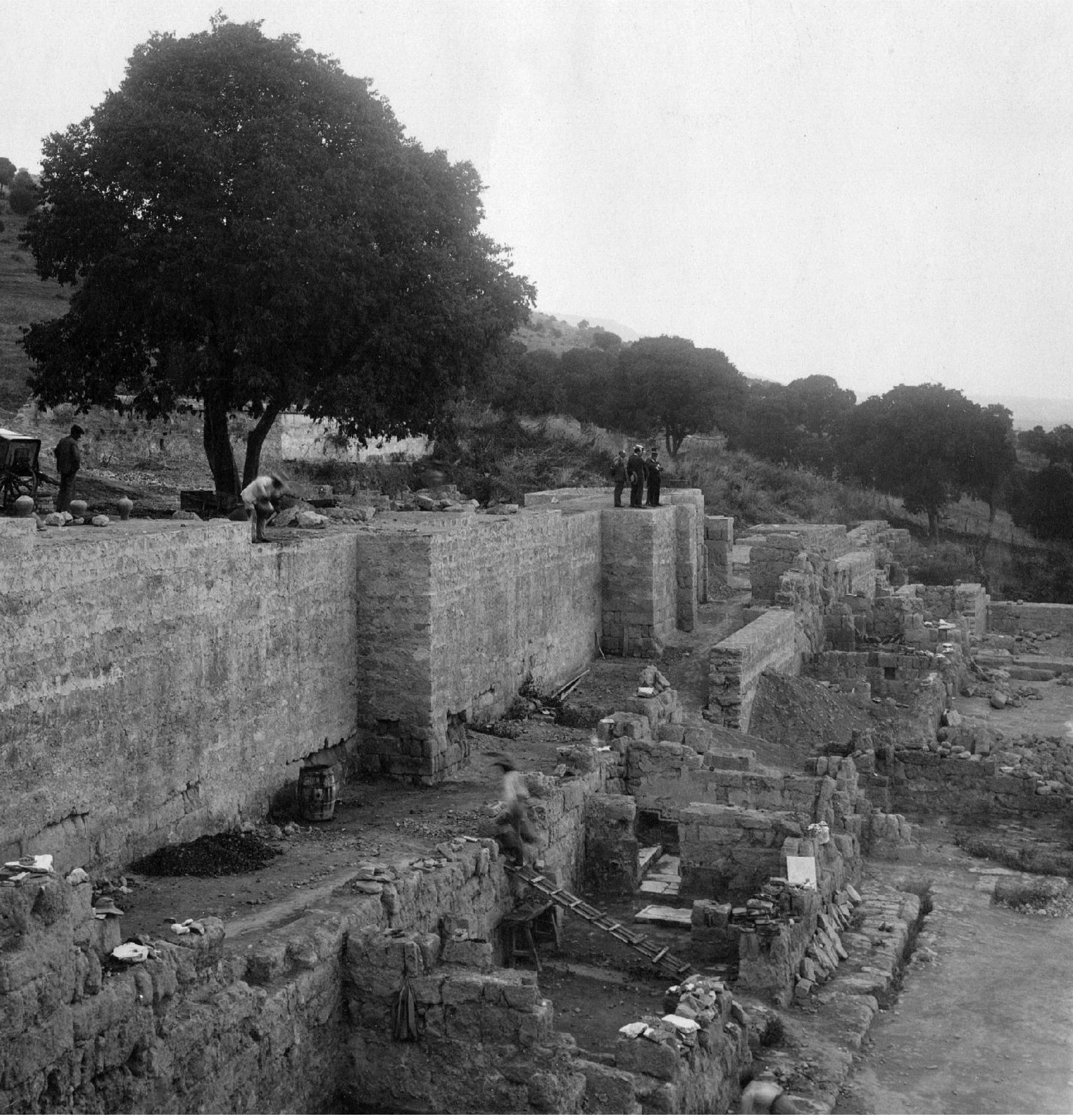




\title{
Las restauraciones de la Alhambra, Madīnat al-Zahrā' e Itálica en los libros de viajes (1940-1975)
}

The restorations of the Alhambra, Madinat al-Zahrā' and Itálica in travel books (1940-1975)

\author{
Victoria Sánchez Mellado \\ Universidad Pablo de Olavide, Sevilla, Espańa \\ vsanmel@upo.es \\ https://orcid.org/0000-0003-0651-5315
}

\section{Resumen}

En el siguiente artículo se analizarán las diversas opiniones escritas por los viajeros extranjeros que vinieron a Andalucía durante el régimen de Franco en sus libros de viajes sobre las restauraciones realizadas en la Alhambra, Madīnat al-Zahrä̀ e Itálica y cómo evolucionaron conforme a los trabajos que los restauradores estaban realizando en esos mismos años. En general, los autores analizados podían tanto aprobar estos trabajos como desaprobarlos o criticarlos por la pérdida de valores del pasado que conllevaban y la dificultad por encontrarse con la grandiosidad de unos monumentos que la litera-

\section{Abstract}

This paper aims to articulate the different opinions written by the foreign travelers who came to Andalusia during the Franco regime in their travel books about the restorations carried out in the Alhambra, Madinat al-Zahrä and Itálica and how they developed according to the works that the restorers were performing in those same years. In general, the authors could approve these works as well as disapprove or criticize them for the loss of values of the past that they implied and the difficulty of encounter the grandeur of monuments that literature and romantics diffused and idealized. Along

Cómo citar este trabajo / How to cite this paper

SÁNCHEZ MELLADO, Victoria, "Las restauraciones de la Alhambra, Madīnat al-Zahrā' e Itálica en los libros de viajes (1940-1975)", Atrio. Revista de Historia del Arte, n. ${ }^{\circ} 24,2018$, págs. 154-169.

Copyright (c) 2018 Victoria Sánchez Mellado. Este es un artículo de acceso abierto distribuido bajo los términos de la licencia Creative Commons AttributionNonCommercial-ShareAlike 4.0. International License (CC BY-NC-SA 4.0).

Este artículo ha sido realizado en el marco del Proyecto I+D "Ruinas, expolios e intervenciones en el patrimonio cultural" (DER2014-52947-P), financiado por el Ministerio de Economía y Competitividad y adscrito a la Universidad Pablo de Olavide, Sevilla, España. 
tura y los románticos difundieron e idealizaron. Junto a ello, los viajeros también resaltarían si se podían ver o no diferencias entre el estado original y el restaurado.

Palabras claves: Restauración; libros de viajes; régimen de Franco; Alhambra; Madīnat al-Zahrā’ Itálica. with it, travelers would also emphasize whether one could see differences between the original state and the restored one.

Keywords: Restoration; travels books; Franco regime; Alhambra; Madinat al-Zahrä; Itálica.

Introducción

En el siguiente artículo se pretende mostrar las diferentes opiniones que fueron escritas por los autores de libros de viajes tras sus periplos por la Andalucía franquista sobre los trabajos de restauración y las excavaciones que se habían realizado o se estaban llevando a cabo en los conjuntos patrimoniales de la Alhambra, Madīnat al-Zahrā’ e Itálica. Monumentos y yacimientos arqueológicos que constituyen oportunos ejemplos de las diferentes vicisitudes por las que tuvo que pasar el patrimonio andaluz a lo largo de su historia: años, cuando no siglos, de abandono, expolios cometidos por los propios vecinos o por tropas extranjeras, uso de sus materiales para nuevas construcciones o destrucciones a causa de diversas guerras.

El análisis de este tipo de narrativa permitirá conocer la visión que sobre las restauraciones tuvieron personas caracterizadas por ser principalmente europeas (aunque también se han analizado libros de americanos) y por tener la capacidad de plasmar por escrito no solo sus vivencias, sino también aspectos relativos a la historia del país y la historia del arte de una manera amena y entretenida, tras realizar un extenso recorrido por España que duraba, en la mayoría de los casos, varias semanas.

De entre todos los que se han estudiado, se podrían destacar las descripciones patrimoniales de la escritora Rose Macaulay, que recorrió Andalucía en 1948 leyendo la guía Baedeker y otros libros sobre la región ${ }^{1}$; las obras del hispanista Gerald Brenan, en las que relató su reencuentro a finales de la década de los cuarenta con las tierras que tuvo que abandonar por el estallido de la Guerra Civil'² o el recorrido que Penelope Chetwode realizó en 1961 por las montañas andaluzas junto a su caballo La Marquesa ${ }^{3}$. Además, también sobresalen otros relatos interesantes como los de Peter Johnston-Saint ${ }^{4}$ y Sacheverell Sitwell ${ }^{5}$, en la primera y en la segunda mitad de la década de los cuarenta, respectivamente; los de Marjorie Grice-Hutchinson ${ }^{6}$ en 1951 y R. A. N. Dixon ${ }^{7}$ y James Reynolds ${ }^{8}$ en 1953; y el de John Langdon Davies a principio de los setenta.

Todos ellos deseaban observar unos determinados elementos del país, ya fuesen patrimoniales, paisajísticos o sociológicos, que arrastraban las influencias de las expectativas que de ellos tenían con anterioridad a la realización del viaje y que conformarían la posterior visión que reflejarían en cada relato. Esas expectativas

1. MACAULAY, Rose, Fabled shore. From the Pyrenees to Portugal, Gran Bretaña, Arrow Books, 1959.

2. BRENAN, Gerald, Al sur de Granada. Un inglés en la Alpujarra, Barcelona, Tusquets Editores S. A., 2003 y BRENAN, Gerald, La faz de España, Barcelona, Plaza \& Janes Editores S. A., 1985. En Al sur de Granada Brenan narró el viaje que realizó antes de la Guerra Civil. Sin embargo, se incluye en este análisis porque en el último capítulo quiso contar su reencuentro con la Alpujarra durante la posguerra.

3. CHETWODE, Penelope, Two middle-aged ladies in Andalusia, Londres, John Murray, 1963.

4. JOHNSTON-SAINT, Peter, Castanets and carnations, Londres, Heath Cranton Ltd., 1946.

5. SITWELL, Sacheverell, Spain, Londres, B. T. Batsford, 1961. Autor también de Southern Baroque art (1924).

6. GRICE-HUTCHINSON, Marjorie, Un cortijo en Málaga, Málaga, Editorial Ágora, 2001.

7. DIXON, R. A. N., Spanish rhapsody, Londres, Robert Hale Ltd., 1955.

8. REYNOLDS, James, Fabulous Spain, Nueva York, G.P. Putnam's Sons, 1953. Autor también de Baroque splendour (1950).

9. LANGDON-DAVIES, John, Spain, Londres, B. T. Batsford Ltd., 1971. Autor también de Gathering from Catalonia (1953). 
residían, de manera general, en el encuentro con una cultura en la que todavía fuesen visibles sus orígenes y sus elementos más intrínsecos y característicos. Cualidades que, dentro del ámbito andaluz, iban a seguir estando conectadas con los recuerdos de Las mil y una noches, los Cuentos de la Alhambra y las remembranzas de Richard Ford y Théophile Gautier, a pesar del evidente paso del tiempo y de los cambios provocados por el desarrollo de las sociedades contemporáneas. Concretamente, los turistas que se han analizado anhelaban toparse, eminentemente, con ese pasado hispanomusulmán que la literatura y los románticos difundieron e idealizaron ${ }^{10}$.

\section{Las restauraciones}

Antes de conocer cómo fueron descritas las actuaciones restauradoras en cada uno de los monumentos escogidos es necesario precisar que estas comenzaron a ser mencionadas por los viajeros en sus libros con más frecuencia desde las últimas décadas del siglo XIX y a lo largo del XX, incrementándose en los años de la posguerra ${ }^{11}$. La causa de este aumento no solo radica en el desarrollo de la restauración como disciplina, sino también en los efectos que la Guerra Civil provocó en el patrimonio ${ }^{12}$, pues los autores analizados solían aludir a ella, junto al paso del tiempo y al abandono, para esclarecer la deficiente situación en la que se encontraba ${ }^{13}$.

A consecuencia de ello y partiendo de los avances que, relativos a la legislación patrimonial se produjeron durante la dictadura de Primo de Rivera y la Segunda República ${ }^{14}$, se fueron creando diversos organismos para la protección monumental como la Junta Conservadora del Tesoro Artístico, creada por Queipo de Llano tan solo veinte días después del inicio del conflicto en la quinta zona (Cáceres, Badajoz, Huelva, Córdoba, Sevilla, Cádiz e Islas Canarias) o el Servicio de Defensa del Patrimonio Artístico Nacional con Comisarías de Zonas ${ }^{15}$, creado en 1938 y que dividió Andalucía en Occidental (provincias de Huelva, Sevilla, Córdoba y Cádiz, con extensión a Marruecos e Islas Canarias) y Oriental (provincias de Jaén, Granada y Málaga, con extensión a Baleares). Y aunque en 1960 pasarían a ser diez zonas, en 1940 se dividió el territorio en siete sectores quedando, los que aquí interesan, de la siguiente manera: la sexta zona con las provincias de Sevilla, Córdoba, Badajoz, Huelva, Cádiz, Tenerife, Las Palmas y las colonias españolas en África; y la séptima, incluyendo las provincias de Granada, Málaga, Almería, Jaén, Murcia y las plazas de Soberanía española y el Norte de África. En cada una de ellas se estableció un arquitecto conservador: Félix Hernández Giménez y Francisco Prieto-Moreno, respectivamente ${ }^{16}$.

10. Véase, por ejemplo, las comparaciones de Córdoba y Granada con ciudades orientales y africanas: BRENAN, Gerald, Al sur de granada..., op. cit., pág. 132; MORTON, Henry Vollam, A stranger in Spain, Londres, Methuen \& Co. Ltd., 1959, págs. 200-201; HAYCRAFT, John, Babel in Spain, Londres, Hamish Hamilton, 1958, pág. 12; LEE, Laurie, A rose for winter, Nueva York, Penguin Books, 1971, pág. 60; y JOHNSTON-SAINT, Peter, Castanets and carnations..., op. cit., pág. 75.

11. Tras la guerra, las actuaciones en el patrimonio fueron muy frecuentes, siendo incluso "uno de los sectores prioritarios de la actividad estatal". ROMERO GALLARDO, Aroa, Prieto-Moreno, arquitecto conservador de la Alhambra (1936-1978): razón y sentimiento, Granada, Patronato de la Alhambra y Generalife, Editorial Universidad de Granada, 2014, pág. 59.

12. La mayoría de los daños causados durante la citada contienda en los monumentos fueron achacados por los viajeros al bando republicano por la quema y el saqueo de las iglesias.

13. Sin olvidar otros conflictos como la Guerra de la Independencia española que también afectó al patrimonio y que, igualmente, fue denunciada en estos relatos.

14. ESTEBAN CHAPAPRÍA, Julián, La conservación del patrimonio español durante la II República (1931-1939), Barcelona, Fundación Caja de Arquitectos, 2007.

15. GÓMEZ DE TERREROS GUARDIOLA, María del Valle, "La conservación del patrimonio arquitectónico sevillano, 1936-1940. Del inicio de la Guerra Civil a la consolidación de la Comisaría de la Sexta Zona del SDPAN", Temas de estética y arte, n. ${ }^{\circ} 23,2009$, págs. 351-390, 355-358, 360 y 364.

16. ESTEBAN CHAPAPRÍA, Julián, "El primer franquismo ¿La ruptura de un proceso en la intervención sobre el Patrimonio?", CASAR PINAZO, José Ignacio y ESTEBAN CHAPAPRÍA, Julián (eds.), Bajo el signo de la victoria. La conservación del patrimonio durante el primer franquismo (1936- 


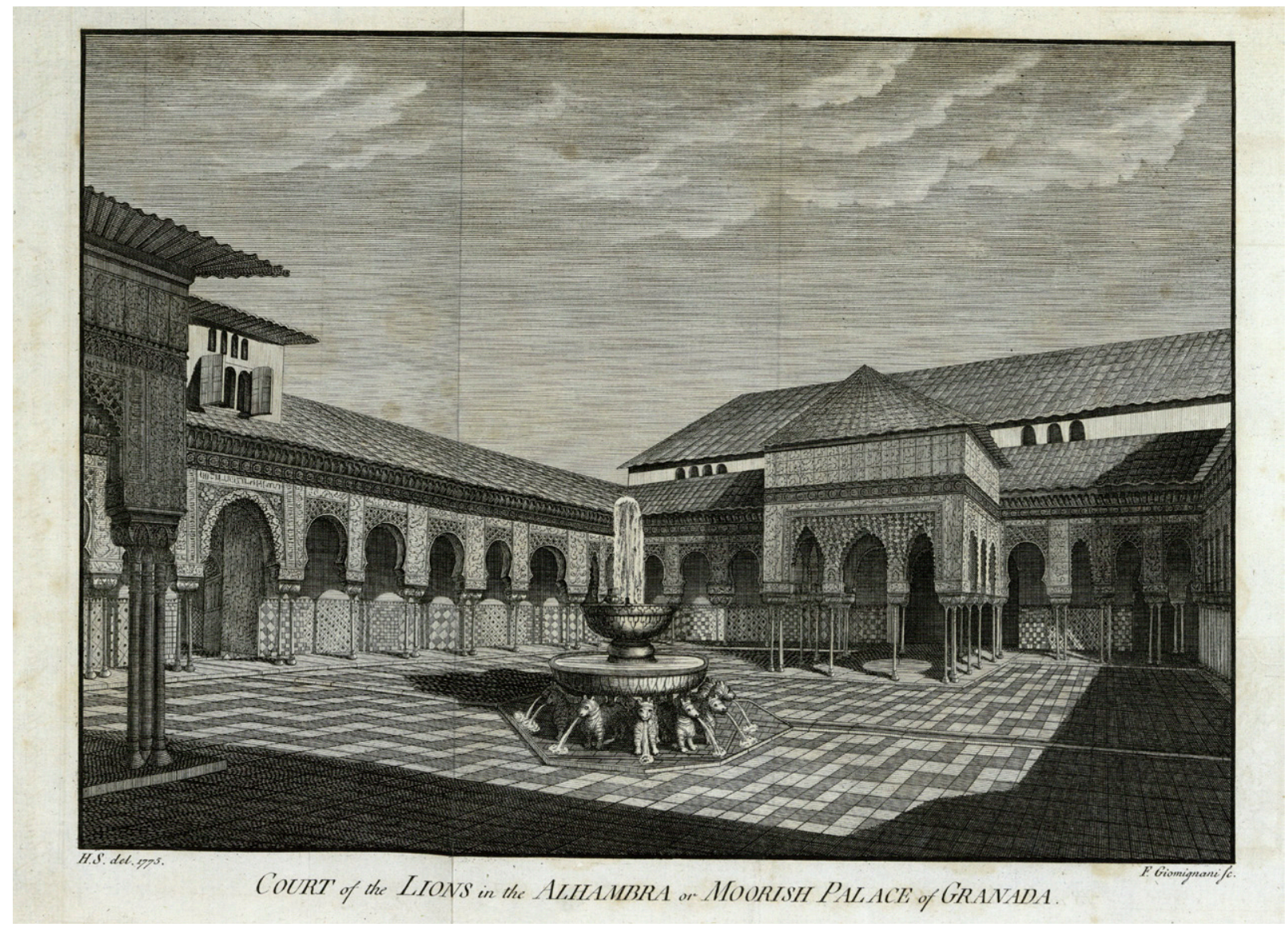

Fig. 2. Patio de los Leones de la Alhambra. Fuente: SWINBURNE, H., Travels through Spain, in the years 1775 and 1776 . In which several monuments of Roman and Moorish architecture are illustrated by accurate drawings taken on the spot, vol. I, London, printed by J. Davis; for P. Elmsly, 1787, pág. 278. @ Biblioteca Nacional de España.

Finalmente, antes de ver más detalladamente las diferentes opiniones relativas a las restauraciones llevadas a cabo en la Alhambra, Madīnat al-Zahrä ${ }^{-17}$ e Itálica hay que decir que estas actuaciones generaron diversidad de opiniones en los relatos analizados. Algunos las consideraron negativas por la pérdida de los valores del pasado y mientras ciertos viajeros no las aprobaban, otros las consideraban como adecuadas. Junto a ello, también existió quien no distinguía los posibles cambios derivados de las mismas, como le ocurrió al periodista y escritor Henry Vollam Morton al visitar la Alhambra a mediados de $1950^{18}$; y aquellos otros que sí fueron capaces de vislumbrar las diferencias existentes entre el estado original y el restaurado. Ejemplo de esto último se encuentra en el libro de Rose Macaulay, fruto de su viaje realizado en 1948, y en sus calificativos de

1958), Valencia, Pentagraf, 2008, págs. 21-70 y 41. De manera general, en las diferentes actuaciones realizadas durante estos años en España "prevaleció un retorno a la 'unidad de estilo' aprovechando los deterioros de los edificios, una búsqueda de la exaltación de su monumentalidad, y cuando los daños eran muy graves, reconstrucciones y reintegraciones estilísticas". RIVERA BLANCO, Javier, "Consideración y fortuna del patrimonio tras la guerra civil: destrucción y reconstrucción del patrimonio histórico (1936-1956). La restauración monumental", ibídem, pág. 97. Además, hay que tener en cuenta que "el gobierno franquista dotó en su fase inicial al patrimonio de un valor trascendente, dotándolo de una importante significación ideológica y política, como reflejo del bando protector de la Historia de España y de sus valores culturales más profundos". Ibídem, pág. 95.

17. Con relación a estos dos conjuntos, véase: GARCÍA CUETOS, María Pilar, El lenguaje de las Bellas Construcciones. Reflexiones sobre la recepción y la restauración de la arquitectura andalusí, Granada, Editorial Universidad de Granada, 2016.

18. MORTON, Henry Vollam, A stranger in Spain..., op. cit., pág. 214. 
"mal gusto, ordinariez y vulgaridad"19 concernientes a las restauraciones realizadas, tanto en el siglo XIX como en la siguiente centuria, en las iglesias y catedrales espańolas -sin concretar ninguna-, ya que, según ella, estas actuaciones acababan conformando "palimpsestos" 20 .

\section{La Alhambra}

La Alhambra sirve como ejemplo de cómo las guerras, el abandono o los diversos sucesos que damnificaron los monumentos espańoles, por una parte, y las restauraciones tendentes a mitigar el efecto de las anteriores, por otra, influyeron considerablemente en las descripciones que los viajeros escribieron sobre los conjuntos arquitectónicos. De manera general, se pueden clasificar a los autores analizados en dos grupos de acuerdo al grado de aceptación de las restauraciones de la Alhambra. Por un lado, aquellos que las vieron como algo positivo porque suponían un cambio con respecto a toda la historia a la que tuvo que enfrentarse el monumento. En este apartado situaríamos a Henry Vollam Morton, W. T. Blake y James Reynolds. Y, por otro lado, aquellos que las consideraron como el germen de la pérdida de la autenticidad del conjunto, donde encuadraríamos a Churton Fairman, Rose Macaulay, Arland Ussher y John Langdon-Davies porque, según ellos, la Alhambra había sido más renovada y reconstruida que restaurada en su estado original.

Estos autores elogiaron los Cuentos de la Alhambra (1832) de Washington Irving por la notoriedad y la popularidad que gracias a esa obra alcanzó el conjunto nazarí, sopesando, incluso, que sin ella la Alhambra habría terminado en ruinas ${ }^{21}$. Pero, a su vez, deploraron que el conjunto hubiese sido refugio para contrabandistas, ladrones, "personajes sospechosos" y tropas napoleónicas ${ }^{22}$, puesto que ello provocó su descuido, saqueo, profanación y la conversión de sus estancias en establos para burros o en alojamiento para cualquiera $^{23}$. Opiniones que ignorarían el cúmulo de intervenciones conservadoras y restauradoras que, con anterioridad a la Guerra Civil y desde mediados del siglo XIX con Rafael Contreras y, posteriormente, con Mariano Contreras, Modesto Cendoya y Leopoldo Torres Balbás, se efectuaron en el monumento ${ }^{24}$.

Estos trabajos, continuados tras la Guerra Civil por Francisco Prieto-Moreno ${ }^{25}$, permitieron a los autores que se han analizado comparar lo que observaron en sus visitas con relatos de viajes anteriores, como lo hizo el periodista Henry Vollam Morton tras visitar el conjunto en 1950.

Morton primero empleó a Henry Swinburne, viajero de mediados del siglo XVIII, para hacer partícipe al lector de que la imagen que se podía ver del Patio de los Leones en el primer volumen del Travels through

19. MACAULAY, Rose, Fabled shore..., op. cit., pág. 12

20. Ibídem.

21. LODER, Dorothy, Spain and her people, Londres, Lutterworth Press, 1961, pág. 103.

22. Ibídem.

23. MACAULAY, Rose, Fabled shore..., op. cit., pág. 162.

24. ORDIERES DÍEZ, Isabel, Historia de la restauración monumental en España: (1835-1936), Madrid, Instituto de Conservación y Restauración de Bienes Culturales, 1995, págs. 351-398. También se puede consultar: ÁLVAREZ LOPERA, José, La Alhambra entre la conservación y la restauración (1905-1915), Granada, Universidad de Granada, Departamento de Historia del Arte, 1977; y BARRIOS ROZÚA, Juan Manuel, Alhambra romántica. Los comienzos de la restauración arquitectónica en España, Granada, Patronato de la Alhambra y Generalife, 2016.

25. Quien en 1937 había redactado un plan con los futuros trabajos en la Alhambra que incluía: "consolidación de las murallas, cubierta de la Torre de Armas, techo de la Sala de la Barca, excavaciones en el Partal, ordenación de los jardines del Partal, excavaciones y ordenación del Secano, excavación y ordenación de la Huerta de san Francisco y restablecimiento de los accesos primitivos a la Alcazaba". ESTEBAN CHAPAPRÍA, Julián, "El primer...", op. cit., pág. 56. Para conocer más sobre sus trabajos en la Alhambra véase: ROMERO GALLARDO, Aroa, Prieto-Moreno..., op. cit. 
Spain, in the years 1775 and 1776 (1779) de Swinburne ${ }^{26}$ (Fig. 2) era idéntica, en su opinión, a la que él pudo observar a mediados del siglo XX, tan solo observando diferencias en el tipo de suelo y en la segunda taza de la fuente que, según él, era "bastante fea" ${ }^{27}$. Idea que, por otro lado, parece no tener en cuenta todo el conjunto de actuaciones que, concretamente en el Patio de los Leones, se realizaron.

Además, Morton insistió, nuevamente, en esa idea de unas restauraciones poco reconocibles al comparar lo que él pudo contemplar con el relato de Richard Ford ${ }^{28}$, escrito en las primeras décadas de 1830 y, por tanto, con anterioridad al comienzo de las actuaciones de Rafael Contreras en el conjunto ${ }^{29}$. De este cotejo, Morton escribió que "cualquiera que haya leido el relato de Ford sobre la decadencia de la Alhambra se preguntará qué parte del edificio actual es verdadero y cuánto es restaurado"30.

Otros autores también quisieron señalar la destreza de las actuaciones llevadas a cabo en la ciudad palatina y lo difícil que les resultaban identificarlas. Precisamente, W. T. Blake, autor de otros libros de viajes como Portuguese journey (1963), relató en 1956 que los trabajos en las distintas salas "se habian hecho tan bien que a las personas corrientes les resultaría difícil decir dónde terminaba la obra original y dónde comenzaba la copia"31. A diferencia de la de Morton, esta opinión no se basaba en ideas previas tomadas de otros viajeros, como se acaba de ver con Swinburne o Ford, sino que se apoyaba en el propio conocimiento que Blake tuvo del monumento tras visitarlo veinte años antes. Gracias a que esa opinión se fundamentaba en el hecho de haber conocido la Alhambra en dos momentos diferentes, es decir, justo tras las actuaciones de Torres Balbás y, posteriormente, mientras en ella trabajaba Prieto-Moreno, se puede apreciar cómo notó un mayor número de actuaciones $^{32}$ en su segunda visita que le llevaron a considerar esa escasa diferencia entre original y restauración.

También es reseñable la reflexión de James Reynolds, arquitecto que demostró profundos conocimientos de historia del arte en su Fabulous Spain (1953). Él, conocedor tal vez de otras actuaciones en la Alhambra o en diversos monumentos que no respetaban la obra original y estaban realizadas bajo presupuestos menos objetivos y siendo consciente, además, de la difícil historia que padeció el conjunto, calificó como "milagro de restauración" el que los "palacios hubiesen sido restaurados siguiendo su antigua belleza" ${ }^{3}$, alabando, por consiguiente, los criterios restauradores que se emplearon en la Alhambra.

26. SWINBURNE, Henry, Travels through Spain, in the years 1775 and 1776. In which several monuments of Roman and Moorish architecture are illustrated by accurate drawings taken on the spot, vol. I, Londres, printed by J. Davis; for P. Elmsly, 1787, pág. 278.

27. MORTON, Henry Vollam, A stranger in Spain..., op. cit., pág. 214 . En 1945 se eliminó el surtidor central y se desmontó la taza superior de la fuente. ROMERO GALLARDO, Aroa, Prieto-Moreno..., op. cit., pág. 107.

28. FORD, Richard, A handbook for travellers in Spain, Londres, John Murray, Albemarle Street, 1882, págs. $396-416$.

29. Entre otras actuaciones realizadas por él, se podría citar la conocida modificación de la cubierta de uno de los templetes del Patio de los Leones, considerada por Torres Balbás como "caprichosamente pintoresca". Citado en ESTEBAN CHAPAPRÍA, Julián, Leopoldo Torres Balbás. Un largo viaje con la Alhambra en el corazón, Valencia, Pentagraf, 2012, pág. 183.

30. MORTON, Henry Vollam, A stranger in Spain..., op. cit., pág. 214. En el fragmento en el que Ford describió la Alhambra se pueden encontrar alusiones a los daños provocados por las tropas francesas y a las restauraciones realizadas por Rafael Contreras (aunque él fue nombrado restaurador adornista del conjunto en 1847). FORD, Richard., A handbook..., op. cit., págs. 399, 403, 405 y 407. Por otro lado, según Esteban Chapapría "no puede sino valorarse positivamente, en el panorama nacional de aquellos años, el trabajo de Prieto-Moreno como conservador de la Alhambra, en un personaje preocupado por las tendencias paisajistas y, en parte, lastrado por un vocabulario tradicional y esquemáticamente historicista". ESTEBAN CHAPAPRÍA, Julián, "El primer...", op. cit., pág. 56.

31. BLAKE, Wilfred Theodore, Spanish journey or springtime in Spain, Londres, Alvin Redman Limited, 1957, pág. 116. Igualmente, el comerciante de vinos T. A. Layton, que estuvo en el conjunto en unas fechas próximas a las de Henry Vollam Morton (1958 o 1959), también expresó una opinión parecida al alabar la habilidad con la que fueron realizados los trabajos de restauración de la Torre de Comares. No obstante, él sí percibió que la mayoría de las decoraciones interiores de esa sala, sobre todo los mosaicos, no estaban en su estado original. LAYTON, Thomas Arthur, Wines and castles of Spain, Londres, New York, Sydney, Toronto, White Lion Publishers, 1974, pág. 74.

32. BLAKE, Wilfred Theodore, Spanish journey..., op. cit., pág. 116.

33. REYNOLDS, James, Fabulous Spain..., op. cit., pág. 108. 
Todas estas opiniones se oponen a las de otros viajeros que, como Rose Macaulay ${ }^{34}$, Arland Ussher o John Langdon-Davies se mostraron críticos, aunque con ciertas matizaciones, con las restauraciones. Concretamente, en la década de los cincuenta, el británico Arland Ussher expresó cómo en la Alhambra sentía que "la reconstrucción había ido un poco más allá de las 'reparaciones" 35 . Además, aunque lo entendía como algo lógico porque, en su opinión "si algo es inocentemente reproducible, seguramente debería ser la yesería, que en primer lugar se aplicó con moldes" 36 , consideró que esa misma capacidad de copia de los arabescos era "la fuente de una de nuestras insatisfacciones" ${ }^{37}$. Posteriormente, el escritor, periodista y autor de Gathering from Catalonia (1953), Langdon-Davies, que visitó el conjunto a inicios de la década de 1970, escribió, siguiendo un parecer similar al formulado por Ussher, que la Alhambra había sido más "renovada en lugar de restaurada en su antiguo estilo"38. Aunque, por su parte, acabó matizando que "solo en los últimos tiempos habia sido tratada con seriedad desde el punto de vista arquitectónico"39.

No obstante, más que la posible pérdida material, lo que de verdad denunciaban era la merma de los valores inmateriales -relacionados con el orientalismo del que es buen exponente la Alhambra y con los personajes que la habitaron- que eran considerados como característicos del conjunto y que Macaulay situó "en la cima de las destrucciones" ${ }^{40}$. Opiniones a las que habría que añadir el incremento de turistas característico de estos años y su negativa influencia en la imagen que de la ciudad palatina se tenía ${ }^{41}$.

Volviendo a Arland Ussher, este británico ofreció, además, una reflexión muy interesante en la cual se confrontan las dos versiones que se han escrito en este apartado sobre las restauraciones: las que ambicionaban el mantenimiento del estado original (la autenticidad que demandaban algunos) y las que aplaudían las diferentes actuaciones realizadas, por la salvación que implicaba, según otros:

"En sus extremos, ambas partes de la discusión [sobre la restauración] son románticas: la que argumenta que el tiempo colabora en la belleza, y la que considera que el pasado debe mantenerse. La primera podría llamarse la concepción del platonista, para quien el cambio y la decadencia inspiran pensamientos sublimes y piadosos; la segunda es más bien la de un hegeliano, que ve la historia como un paseo por una galería, y el cambio simplemente como una yuxtaposición de formas perfectas. Pero el tiempo, está claro, puede ser un colaborador bastante severo; una ruina o un montón de piedras no es un edificio, y carece de las bellezas de la totalidad y de la relación entre las partes"42.

Finalmente, cabe destacar la conversación que mantuvo P. Johnston-Saint, mientras visitaba la Alhambra junto a su primo Drake, con Leopoldo Torres Balbás ${ }^{43}$. El restaurador pasearía junto a ellos por las

\footnotetext{
34. MACAULAY, Rose, Fabled shore... op. cit., pág. 163.

35. USSHER, Arland, Spanish mercy, Londres, Victor Gollancz Ltd., 1959, pág. 161.

36. Ibídem.

37. Ibídem.

38. LANGDON-DAVIES, John, Spain..., op. cit., pág. 158.

39. Ibídem, págs. 158-159.

40. MACAULAY, Rose, Fabled shore..., op. cit., pág. 163. Igual opinión mostró P. Johnston-Saint al considerar que los palacios nazaríes estaban envueltos de un "aire cargado de muerte y deterioro". JOHNSTON-SAINT, Peter, Castanets and carnations..., op. cit., pág. 76.

41. Para el escritor y periodista Churton Fairman que había visitado España en la década de 1940, es decir, antes del desarrollo del turismo de masas, esta "reliquia" como él la llamó "había sido tan concienzudamente restaurada y 'turistificada' [...] que su atmósfera es tan fría como una pieza de museo". Además, Fairman lamentó que las restauraciones hubiesen reformado también su alma. FAIRMAN, Churton, Another Spain, Londres, Museum Press Ltd., 1952, pág. 157.

42. USSHER, Arland, Spanish mercy... op. cit., pág. 161.

43. Johnston Saint, que realizó su viaje en la primera mitad de la década de 1940 cuando Torres Balbás ya había dejado de ser el restaurador de la Alhambra, le presentó como "el arquitecto y conservador". El hecho de hacerlo de esa manera lleva a la confusión de no saber si se refería a su
} 
salas y patios, les leería algunas inscripciones como las que había en la Sala de los Embajadores ${ }^{44}$, les encendió el mecanismo de la fuente del Patio de los Leones ${ }^{45}$, les explicó el desarrollo de la decoración que estaban observando ${ }^{46}$ y les llevó a salas que normalmente no se abrían al público ${ }^{47}$.

\section{Madīnat al-Zahrā'}

A diferencia de la Alhambra, las actuaciones en Madīnat al-Zahrā fueron percibidas por los viajeros como escasas e insuficientes, lo que implicaba que incluso se recomendase el uso del ingenio y la invención para poder llegar a comprender este conjunto que muchos no dudaban en imaginárselo como uno de los más grandiosos.

No obstante, aunque percibidos como exiguos, ya desde el siglo XIX diversos testimonios resaltarían la importancia que se concedía a Madīnat al-Zahrā. Si en la década de 1820, el marine estadounidense Alexander Slidell Mackenzie había buscado en vano cualquier resto de este conjunto -que sí describió con mucho detalle ayudándose de las traducciones de los historiadores árabes ${ }^{48}$-; a mediados de la centuria, en fechas muy próximas al primer intento de realizar excavaciones por parte de Pedro de Madrazo y Pascual de Gayangos $^{49}$ en la ciudad califal, la inglesa Louisa Tenison escribió sobre un muro que encerraba una porción de terreno en la cual se podría encontrar el palacio ${ }^{50}$. A pesar de ello, Tenison también precisó que no existía "ni una huella de la ciudad: las rosas florecen desatendidas en las laderas de la Sierra, y el país construido para ser un paraiso se ha dejado abandonado por la mano del hombre" 51.

Asimismo, Cecilia Hill, autora de otros libros de viajes como Versailles: its life and history y Fifty miles round Paris, informó, ya en las primeras décadas del siglo XX, y sin concretar en qué parte en concreto que "cada vez se estaban excavando más restos" 52 . Fue en esa época, concretamente en 1911, cuando Ricardo Velázquez Bosco empezó con las labores de excavación ${ }^{53}$, que fueron continuadas desde 1923 por una comisión en cuyos trabajos participaron Rafael Jiménez Amigo, Rafael Castejón, Ezequiel Ruiz Martínez, Joaquín Navascués y Félix Hernández ${ }^{54}$ (Fig. 1). En ellas se empezó a trabajar por la consolidación y la restauración del conjunto, realizando a partir de 1944 las excavaciones del salón de Abd al-Rahman III y las

profesión o a su función dentro de la ciudad nazarí. Esto último sería un error dada las fechas en las que se realizó el viaje. JOHNSTON-SAINT, Peter, Castanets and carnations..., op. cit., pág. 76.

44. Ibídem, pág. 77. Decía Johnston Saint que mientras Torres Balbás leía esas inscripciones su voz resonaba como la de un mullah recitando el Corán en alguna mezquita majestuosa. Ibídem, pág. 81.

45. Ibídem, pág. 77.

46. Ibídem, pág. 79

47. Ibídem, pág. 88.

48. MACKENZIE, Alexander Slidell, A year in Spain, vol. II, Londres, John Murray, 1831, págs. 152-154

49. Quien realizó una exploración en el sitio ocupado por el Jardín Alto. VALLEJO TRIANO, Antonio, "Problemas de gestión y administración de Madinat al-Zahra desde el inicio de su recuperación", Arqueología y territorio medieval, vol. 1, 1994, pág. 18.

50. TENISON, Louisa, Castile and Andalucia, Londres, Richard Bentley, 1853, pág. 486.

51. Ibídem.

52. HILL, Cecilia, Moorish Towns in Spain, Londres, Methuen \& Co. Ltd., 1931, pág. 65.

53. Velázquez Bosco realizó excavaciones en la zona de la Casa Real, el Camino de Ronda Bajo, Edificios Superiores y Vivienda oriental de Servicio. Posteriormente, en 1923, excavaría, en la zona occidental, la vivienda privada del califa y, en la oriental, el Salón Basilical Superior. VALLEJO TRIANO, Antonio, La ciudad califal de Madinat al-Zahrā': arqueología de su excavación, Córdoba, Almuzara, 2010, págs. $22-23$.

54. Posteriormente, en 1975, Rafael Manzano se encargó de las restauraciones en el conjunto. VALLEJO TRIANO, Antonio, "Problemas...", op. cit., págs. 19-20 y 23. Es en este momento cuando se realizó el primer plano topográfico que recogía la extensión y la disposición de las diferentes estructuras. Además, hasta 1936 se completaron "las excavaciones de las edificaciones del escalón superior". VALLEJO TRIANO, Antonio, La ciudad..., op. cit., págs. 36 y 38. Julián Esteban Chapapría determina que algunas actuaciones realizadas en la sexta zona, como, por ejemplo, en los palacios de Madīnat al-Zahrā' fueron "fuertemente recreativas, justamente, por su trascendencia". ESTEBAN CHAPAPRÍA, Julián, "El primer...", op. cit., pág. 55. 
de nuevos espacios, como la mezquita ${ }^{55}$ y todo ello con el rigor y la metodología que caracterizó a las obras de Félix Hernández ${ }^{56}$.

Entrando ya en la época franquista, cabe destacar las ideas expresadas por Johnston Saint y Gerald Brenan. El primero, en la primera mitad de la década de 1940 consideró que las restauraciones se habían hecho a una "escala limitada" y que solo se podían ver los cimientos de los principales edificios ${ }^{57}$. En cuanto al segundo, a finales del mismo decenio y contrariamente a lo escrito por los viajeros que le precedieron, indicó que "hasta hace pocos años ni siquiera se conocía su emplazamiento y los toros pastaban y peleaban entre si donde en otro tiempo las más hermosas mujeres del mundo habian languidecido en sus lechos mientras se atiborraban de pasteles y golosinas" 58 . Añadió, además, en cuanto a los trabajos de restauración que se estaban realizando en los años de su visita que:

"Solo una pequeña área del palacio ha sido excavada hasta el presente; más allá de ella se extienden hectáreas de informes montículos, cubiertos con trepadoras hojas de acantos y pequeñas mandrágoras y los secos tallos del hinojo. El cormorán y el avetoro, la lechuza blanca, y las mariposas marrones y grises, siguen gozando del lugar solo para ellos"59.

Esa pequeña área excavada a la que aludió Brenan seguramente era el palacio de Abd al-Rahman III, en el que se trabajaba desde 1944 y del cual el propio Torres Balbás, en su libro de 1952 explicó que fue un "sensacional hallazgo, por la riqueza y cantidad de su decoración, conservada en parte en los muros y aparecida el resto entre los escombros, en cantidad superior a toda la anteriormente hallada" ${ }^{60}$. No obstante, es necesario entender que, para alguien no experto en la materia, como pudieron ser los viajeros aludidos, esa "escala limitada" o esa "pequeña área" excavada no debía suponer gran cosa en comparación con todo lo que hubiesen podido leer de cómo fue realmente el conjunto.

Posteriormente, John Haycraft, que vino a España con su mujer a partir de 1953 para fundar una academia de inglés en Córdoba, además de destacar los progresivos trabajos de excavación que se iban realizando ${ }^{61}$, informó de cómo se estaban produciendo las restauraciones de Madīnat al-Zahrā’: aludió al escaso dinero que el Estado le dedicaba, a cómo se iban encajando las piedras como si fueran un puzle y terminó añadiendo que sería interesante ver cómo eran realmente las habitaciones porque "será casi como un plató de rodaje"62.

A pesar de oponerse las opiniones de Haycraft y Brenan, no serían las del hispanista las únicas que negarían el avance de las actuaciones que se han mencionado ${ }^{63}$. Así ocurre, por ejemplo, en Iberia. Spanish travels and reflections del escritor estadounidense James Albert Michener. En esta obra, su autor, tras conocer el

55. MUÑOZ DÍAZ, Jesús Miguel, "Madinat al-Zahra. Cronología de un conflicto”, Observatorio del patrimonio histórico español, pág. 3. Comenzando, a finales de la década de 1940, las obras de reconstrucción del salón. VALLEJO TRIANO, Antonio, La ciudad..., op. cit., pág. 42.

56. VALLEJO TRIANO, Antonio, "Problemas...", op. cit., pág. 23. Sin olvidar que, "desde la década de 1930, [existió] un proyecto de recrecido sistemático de sus estructuras, utilizando los fragmentos de sillares, descompuestos, aparecidos en la excavación". VALLEJO TRIANO, Antonio, "Madinat al-Zahra: realidad histórica y presente patrimonial", Awraq: Estudios sobre el mundo árabe e islámico contemporáneo, n. 7, 2013, pág. 133. Para más información sobre los trabajos de Félix Hernández en Córdoba, véase: HERRERO ROMERO, Sebastián, "Félix Hernández y la restauración de la Mezquita-Catedral de Córdoba", Archivo Español de Arte, tomo 88, n. 349, 2015, pág. 13.

57. JOHNSTON-SAINT, Peter, Castanets and carnations..., op. cit., pág. 193.

58. BRENAN, Gerald, La faz..., op. cit., pág. 41.

59. Ibídem, pág. 42.

60. TORRES BALBÁS, Leopoldo, La Mezquita de Córdoba y las ruinas de Madinat Al-Zahra, Madrid, Plus-Ultra, 1952, pág. 149.

61. HAYCRAFT, John, Babel in Spain..., op. cit., pág. 27.

62. Ibídem, págs. 32-33. Véase, para más información sobre los sets islámicos en las películas: RAMíREZ, Juan Antonio, La arquitectura en el cine. Hollywood, la Edad de oro, Madrid, Alianza, 1993, págs. 196 y 198.

63. A pesar de que Torres Balbás en su descripción de 1952 relató que en la terraza elevada "varios montículos revelan la existencia de pabellones 
lugar en la década de los sesenta, reveló interesantes opiniones relativas a las restauraciones. En primer lugar, escribió que sólo se debería visitar la ciudad califal si se poseía una gran imaginación, pues, de lo contrario el viaje sería, según su opinión, "decepcionante e incluso engañoso" ${ }^{4}$. También, tras preguntarse si esa "ladera árida con sus ruinas poco impresionantes" era la gloria del islam ${ }^{65}$ porque tan solo se veían "algunas piedras aqui y alla" y "una única ruina que aún conserva el techo" ${ }^{66}$, escribió que percibir en ellas "la maravilla que alguna vez fue [Madinat al-Zahrä]] requiere fe" ${ }^{67}$. Finalmente, frente a la gran mayoría, que no dudaban de la grandeza ni de la extensión del conjunto, Michener se cuestionaría la veracidad de las fuentes árabes que lo narraban ${ }^{68}$ y que fueron usadas por otros viajeros para describirlo.

Sin embargo, esta posición crítica hacia las ruinas de este conjunto sería posteriormente atenuada tras contemplar la mezquita de Córdoba y la Alhambra. El gran tamaño de la primera le hizo comprender que lo que decían las fuentes árabes sobre Madinnat al-Zahrā' no era imposible ${ }^{69}$. Por su parte, la fragilidad de los materiales de la segunda le llevó entender por qué había desaparecido la ciudad califal ${ }^{70}$.

Sorprende, en definitiva, que, tras visitar el lugar en 1967, Michener escribiese todos estos aspectos y recomendase imaginación y fe, cuando, por esas fechas, Félix Hernández ya llevaba cuarenta y cuatro ańos realizando trabajos de consolidación y restauración. Pero lo cierto es que, no solo en él, sino también en el resto de las opiniones expresadas por los viajeros se deduce la importante demanda de un mayor número de actuaciones para que el conjunto fuese como lo describían las fuentes que consultaron y que explican la difícil lectura que para el viajero común pueden tener los restos conservados y las labores de restauración sobre todo en yacimientos arqueológicos.

Al igual que ocurría para Madīnat al-Zahrā', en Itálica se aprecia cómo a los que visitaron este yacimiento les costaba interpretar lo que observaban. Los autores analizados escribieron sobre unas ruinas de gran extensión en las que priorizaban el anfiteatro sobre el resto y denunciaban, además, el uso que se hacía de estos vestigios para emplearlos en otros edificios.

En general, son escasos los viajeros que escribieron sobre las ruinas de Itálica haciendo hincapié en lo que hay más allá del anfiteatro. Por ello son destacables, aunque en los inicios de la centuria anterior, Alexandre de Laborde y su Voyage pittoresque et historique de l'Espagne (1806-1820) por incluir la imagen de un conocido mosaico descubierto en Itálica en 1799 afirmando que era "uno de los más importantes y mejor conservados que nos ha llegado de la antigüedad"71 (Fig. 3). De tal manera lo creía que incluso se puede encontrar una obra suya titulada Description d'un pavé en mosaique découverte dans l'ancienne ville d'Italica, aujourd'hui le village de

divididos en naves transversales, precedidos de grandes patios" y que en la meseta intermedia se podían ver "las ruinas de un importante edificio aislado, y, más a oriente, la mezquita". TORRES BALBÁS, Leopoldo, La Mezquita de Córdoba..., op. cit., pág. 140.

64. MICHENER, James A., Iberia. Spanish travels and reflections, Nueva York, Random House, 1968, pág. 166.

65. Ibídem, pág. 166.

66. Ibídem.

67. Ibídem, pág. 167.

68. Ibídem.

69. MICHENER, James A., Iberia. Spanish travels... op. cit.

70. Ibídem, pág. 186.

71. LABORDE, Alexandre de, Voyage pittoresque et historique de l'Espagne, tomo segundo, primera parte, París, Pierre Didot L'Ainé, 1812, pág. 
Santiponce près de Séville (1802) en la que de Laborde describió este mosaico, hoy desaparecido, llamado del Circo o de las Musas ${ }^{72}$.

Pero la aportación de este decimonónico francés es una excepción que continúa hasta esta época franquista. Y ello a pesar de que Rodrigo Amador de los Ríos ${ }^{73}$ había realizado trabajos desde el primer decenio del siglo XX, que fueron continuados, a lo largo de dicha centuria, por Andrés Parladé, Juan Mata Carriazo, Francisco Collantes de Terán ${ }^{74}$-trabajando, sin olvidar el anfiteatro, en las habitaciones y en las casas de una manera más sistemática y ordenada ${ }^{75}$, además de realizarse trabajos para la consolidación y la protección de los mosaicos $^{76}$ - y Félix Hernández.

Una excepción a esa ausencia de descripción sobre lo que hay además del anfiteatro se encuentra en el francés Jean Sermet, quien, tras sus investigaciones en las décadas de 1930, principalmente, y 1950, en menor medida, aludió a los trabajos que se estaban llevando a cabo en Itálica y a los "preciosos mosaicos recientemente descubiertos" 77 , añadiendo, además, que "hay centenares de metros cuadrados de estos mosaicos" 78 a los que, como se ha dicho, pocos viajeros prestaron atención.

Estos preferían mostrar ideas como las expresadas por Johnston Saint y Henry Vollam Morton. El primero escribió que, a pesar de haber escuchado mucho sobre los encantos de esta ciudad romana, acabó algo decepcionado pues, en su opinión, la mayoría de los restos no eran dignos de observarse ${ }^{79}$. No obstante, dada la cercanía temporal del viaje de Johnston Saint con los trabajos de Parladé, realizados de 1919 a 1933 y caracterizados por no llevar "un orden lo que se excavaba y [hacerse] de una forma aleatoria" ", se puede entender que considerara que los restos no merecían ser observados, quizás porque los trabajos no fuesen tan sistemáticos como hoy. No así, para el caso de Morton, quien utilizó el término “incoherente" 81 para referirse a estas ruinas tras visitarlas en 1954, cuando los trabajos de restauración estaban ya adelantados. Por suerte, a finales de esta misma década, T. A. Layton consideró el conjunto como una de las más perfectas ruinas

30. Véase para más información sobre este desaparecido mosaico: RUEDA ROIGÉ, Francesc-Josep, "El mosaico del circo documentado en Itálica", Locus amoenus, n. ${ }^{7}$, 2004, págs. 7-25.

72. MAÑAS ROMERO, Irene, Mosaicos romanos de Itálica (II): mosaicos contextualizados y apéndice, Madrid, Sevilla, Consejo Superior de Investigaciones Científicas, Universidad Pablo de Olavide, 2011, págs. 86-90.

73. Las primeras excavaciones oficiales en el conjunto se realizaron de 1781 a 1788, época en la que se descubrirían las esculturas de los desnudos heroicos de Trajano y Adriano. Posteriormente, y tras un nuevo intento por realizar excavaciones de 1839 a 1841, Demetrio de los Ríos excavó, a partir de 1856, el anfiteatro, las dos termas y varias viviendas. CABALLOS RUFINO, Antonio; MARÍN FATUARTE, Jesús y RODRÍGUEZ HIDALGO, José Manuel, Itálica arqueológica, Sevilla, Secretariado de Publicaciones de la Universidad de Sevilla, 2006, págs. 43-46. Véase también: FERNÁNDEZ GÓMEZ, Fernando, Las excavaciones de Itálica y don Demetrio de los Ríos a través de sus escritos, Córdoba, CajaSur, Obra Social y Cultural, 1998.

74. GONZÁLEZ PARRILLA, José María, "Francisco Collantes de Terán Delorme y las excavaciones en Itálica entre 1935 y 1955", Habis, n. 36,2005, págs. 334-335. Andrés Parladé sería el que excavase, desde 1924 a 1933, "gran parte del actual circuito turístico". CABALLOS RUFINO, Antonio; MARÍN FATUARTE, Jesús y RODRÍGUEZ HIDALGO, José Manuel, Las excavaciones..., op. cit., pág. 48.

75. GONZÁLEZ PARRILLA, José María, "Francisco Collantes de Terán...", op. cit., pág. 338.

76. Ibídem, pág. 343.

77. SERMET, Jean, La España del sur, Barcelona, Juventud, 1956, pág. 260. Sermet no especificó si esos trabajos fueron observados en la década de 1930 o en la de los cincuenta.

78. Ibídem.

79. JOHNSTON-SAINT, Peter, Castanets and carnations..., op. cit., pág. 168. Conviene a este respecto hacer mención a la conocida colección arqueológica de la Condesa de Lebrija, escasamente descrita por los viajeros analizados y que cuenta con importantes obras procedentes de Itálica. Más información sobre dicha colección en: AMADOR DE LOS RÍOS, Rodrigo, "El Museo de Antigüedades Italicenses de la Excelentísima Señora Doña Regla Manjón viuda de Sánchez Bedoya, en Sevilla", Revista de Archivos Bibliotecas y Museos, tomo 27, n. $9-12,1912$, págs. 266-289.

80. GONZÁLEZ PARRILLA, José María, "Francisco Collantes de Terán...", op. cit., pág. 335.

81. MORTON, Henry Vollam, A stranger in Spain..., op. cit., pág. 196. 


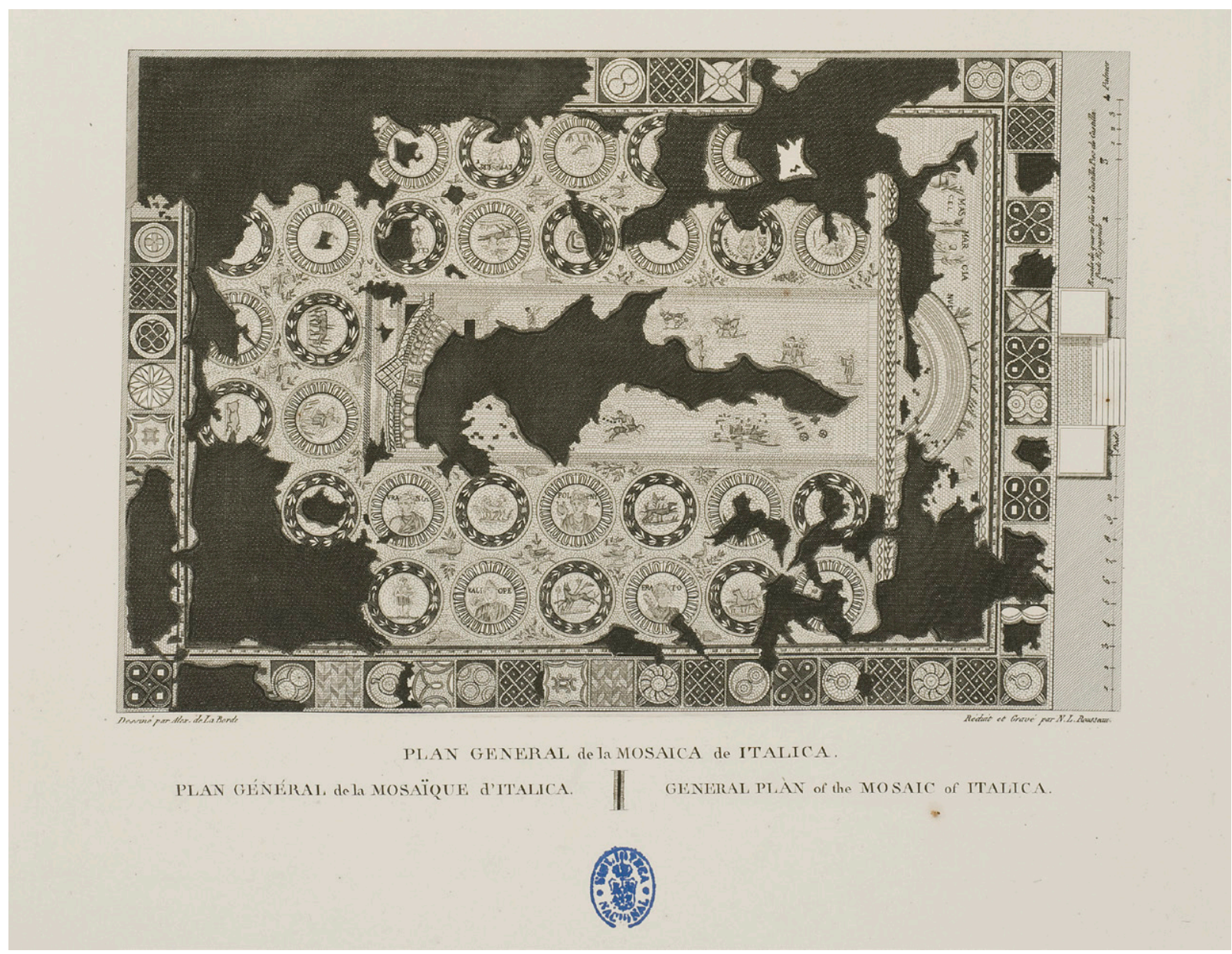

Fig. 3. Mosaico del Circo o de las Musas. Fuente: LABORDE, A. de, Voyage pittoresque et historique de l'Espagne, Tomo segundo, primera parte, París, Pierre Didot L'Ainé, 1812, pág. 30. @ Biblioteca Nacional de España.

romanas de Andalucía ${ }^{82}$. Por lo que podemos ver cómo los trabajos realizados por los restauradores antes mencionados parecen que iban dando sus frutos.

Conclusiones

Del análisis se puede deducir cómo las opiniones respecto a las excavaciones y restauraciones en los monumentos y yacimientos estudiados no mostraban, en muchas ocasiones, la realidad de estos trabajos, pues los viajeros solían preferir más la grandiosidad pasada, descrita por autores anteriores o en fuentes históricas, que las evidentes diferencias con las que se encontraron cuando realizaron su visita a esos lugares. Esto provocaba, además, que en muchas ocasiones, no se entendiese lo que se estaba observando. Si bien es cierto que, entre los que vinieron durante la dictadura de Franco, algunos aplaudieron estos trabajos como se ha visto sobre todo en la Alhambra (tal vez porque sus palacios nazaríes sí han conservado su estructura en pie, al contrario que en Madīnat al-Zahrāa e Itálica), también existieron, incluso de manera más frecuente, quienes, a pesar del avance en los distintos trabajos, escribieron sobre una imagen que era más deseada y añorada que real.

82. LAYTON, Thomas Arthur, Wines and castles of Spain..., op. cit., pág. 144. 
La influencia del orientalismo, principalmente en los conjuntos de la Alhambra y Madīnat al-Zahrä, puede explicar esta discordancia. En ambos, los autores deseaban ver esos fantasmas de reyes moriscos, sultanes, mujeres hermosas y personajes variopintos - usando sus palabras- y no las aglomeraciones y oleadas de turistas con la que se acababan encontrando. De manera que esta ansia de orientalismo, herencia de los decimonónicos, continúa, sin duda alguna, en el periodo analizado. Baste decir que José Ruiz Mas en la clasificación de libros de viajes del siglo XX que presentó en su Libros de viajes en lengua inglesa por la España del siglo XX (2003), incluyó la categoría de "nostálgicos de épocas más románticas" entre otras como "con intenciones propagandisticas pro-franquistas, propagandistico antifranquista, de propaganda pro-turistica y con carácter antropológico y sociológico" ${ }^{\prime 3}$.

Relacionado con lo anterior, la melancolía y la nostalgia que expresaban cuando observaban estos tres conjuntos les llevó a desear haberlos contemplados en sus momentos de máximo esplendor y repletos de aquellos valores intangibles que, por ejemplo, apreciaban en la Alhambra.

\section{Bibliografía}

ÁLVAREZ LOPERA, José, La Alhambra entre la conservación y la restauración (1905-1915), Granada, Universidad de Granada, Departamento de Historia del Arte, 1977.

AMADOR DE LOS RÍOS, Rodrigo, "El Museo de Antigüedades Italicenses de la Excelentísima Señora. Doña Regla Manjón viuda de Sánchez Bedoya, en Sevilla”, Revista de Archivos Bibliotecas y Museos, tomo 27, n. ${ }^{\circ}$ 9-12, 1912, págs. 266-289.

BARRIOS ROZÚA, Juan Manuel, Alhambra romántica. Los comienzos de la restauración arquitectónica en España, Granada, Patronato de la Alhambra y Generalife, 2016.

BLAKE, Wilfred Theodore, Spanish journey or springtime in Spain, Londres, Alvin Redman Limited, 1957.

BRENAN, Gerald, La faz de España, Barcelona, Plaza \& Janes Editores S. A., 1985.

BRENAN, Gerald, Al sur de Granada. Un inglés en la Alpujarra, Barcelona, Tusquets Editores S. A., 2003.

CABALLOS RUFINO, Antonio; MARÍN FATUARTE, Jesús y RODRÍGUEZ HIDALGO, José Manuel, Itálica arqueológica, Sevilla, Secretariado de Publicaciones de la Universidad de Sevilla, 2006.

CHETWODE, Penelope, Two middle-aged ladies in Andalusia, Londres, John Murray, 1963.

DIXON, R. A. N., Spanish rhapsody, Londres, Robert Hale Ltd., 1955.

ESTEBAN CHAPAPRÍA, Julián, La conservación del patrimonio español durante la II República (1931-1939), Barcelona, Fundación Caja de Arquitectos, 2007.

ESTEBAN CHAPAPRÍA, Julián, "El primer franquismo ¿La ruptura de un proceso en la intervención sobre el Patrimonio?”, CASAR PINAZO, José Ignacio y ESTEBAN CHAPAPRÍA, Julián, eds., Bajo el signo de la victoria. La conservación del patrimonio durante el primer franquismo (1936-1958), Valencia, Pentagraf, 2008, págs. 21-70.

ESTEBAN CHAPAPRÍA, Julián, Leopoldo Torres Balbás. Un largo viaje con la Alhambra en el corazón, Valencia, Pentagraf, 2012.

FAIRMAN, Churton, Another Spain, Londres, Museum Press Ltd., 1952.

FERNÁNDEZ GÓMEZ, Fernando, Las excavaciones de Itálica y don Demetrio de los Ríos a través de sus escritos, Córdoba, CajaSur, Obra Social y Cultural, 1998.

83. RUIZ MAS, José, Libros de viajes en lengua inglesa por la España del siglo XX, Granada, Grupo Editorial Universitario y UNED de Jaén, 2003, págs. 109-152. 
FORD, Richard, $A$ handbook for travellers in Spain, Londres, John Murray, Albemarle Street, 1882.

GARCÍA CUETOS, María Pilar, El lenguaje de las Bellas Construcciones. Reflexiones sobre la recepción y la restauración de la arquitectura andalusi, Granada, Editorial Universidad de Granada, 2016.

GÓMEZ DE TERREROS GUARDIOLA, María del Valle, "La conservación del patrimonio arquitectónico sevillano, 1936-1940. Del inicio de la Guerra Civil a la consolidación de la Comisaría de la Sexta Zona del SDPAN", Temas de estética y arte, n. ${ }^{\circ}$ 23, 2009, págs. 353-389.

GONZÁLEZ PARRILLA, José María, "Francisco Collantes de Terán Delorme y las excavaciones en Itálica entre 1935 y 1955”, Habis, n. ${ }^{\circ} 36,2005$, págs. 333-347

GRICE-HUTCHINSON, Marjorie, Un cortijo en Málaga, Málaga, Editorial Ágora, 2001.

HAYCRAFT, John, Babel in Spain, Londres, Hamish Hamilton, 1958.

HERRERO ROMERO, Sebastián, "Félix Hernández y la restauración de la Mezquita-Catedral de Córdoba", Archivo Español de Arte, tomo 88, n. ${ }^{\circ} 349,2015$, págs. 1-18.

HILL, Cecilia, Moorish Towns in Spain, Londres, Methuen \& Co. Ltd., 1931.

JOHNSTON-SAINT, Peter, Castanets and carnations, Londres, Heath Cranton Ltd., 1946.

LABORDE, Alexandre de, Voyage pittoresque et historique de l'Espagne, tomo segundo, primera parte, París, Pierre Didot L'Ainé, 1812.

LANGDON-DAVIES, John, Spain, Londres, B. T. Batsford Ltd., 1971.

LAYTON, Thomas Arthur, Wines and castles of Spain, Londres, New York, Sydney, Toronto, White Lion Publishers, 1974.

LEE, Laurie, A rose for winter, Nueva York, Penguin Books, 1971.

LODER, Dorothy, Spain and her people, Londres, Lutterworth Press, 1961.

MACAULAY, Rose, Fabled shore. From the Pyrenees to Portugal, Gran Bretaña, Arrow Books, 1959.

MACKENZIE, Alexander Slidell, A year in Spain, vol. II, Londres, John Murray, 1831.

MAÑAS ROMERO, Irene, Mosaicos romanos de Itálica (II): mosaicos contextualizados y apéndice, Madrid, Sevilla, Consejo Superior de Investigaciones Científicas, Universidad Pablo de Olavide, 2011.

MICHENER, James A., Iberia. Spanish travels and reflections, Nueva York, Random House, 1968.

MORTON, Henry Vollam, A stranger in Spain, Londres, Methuen \& Co. Ltd., 1959.

MUÑOZ DÍAZ, Jesús Miguel, "Madinat al-Zahra. Cronología de un conflicto”, Observatorio del patrimonio histórico español, págs. 1-31.

ORDIERES DÍEZ, Isabel, Historia de la restauración monumental en España: (1835-1936), Madrid, Instituto de Conservación y Restauración de Bienes Culturales, 1995.

RAMÍREZ, Juan Antonio, La arquitectura en el cine. Hollywood, la Edad de oro, Madrid, Alianza, 1993.

REYNOLDS, James, Fabulous Spain, Nueva York, G.P. Putnam’s Sons, 1953.

ROMERO GALLARDO, Aroa, Prieto-Moreno, arquitecto conservador de la Alhambra (1936-1978): razón y sentimiento, Granada, Patronato de la Alhambra y Generalife, Editorial Universidad de Granada, 2014.

RUEDA ROIGÉ, Francesc-Josep, "El mosaico del circo documentado en Itálica”, Locus amoenus, n. 7, 2004, págs. 7-25.

RUIZ MAS, José, Libros de viajes en lengua inglesa por la España del siglo XX, Granada, Grupo Editorial Universitario y UNED de Jaén, 2003.

SERMET, Jean, La España del sur, Barcelona, Juventud, 1956.

SITWELL, Sacheverell, Spain, Londres, B. T. Batsford, 1961.

SWINBURNE, Henry, Travels through Spain, in the years 1775 and 1776. In which several monuments of 
Roman and Moorish architecture are illustrated by accurate drawings taken on the spot, vol. I, Londres, printed by J. Davis; for P. Elmsly, 1787.

TENISON, Louisa, Castile and Andalucia, Londres, Richard Bentley, 1853.

TORRES BALBÁS, Leopoldo, La Mezquita de Córdoba y las ruinas de Madinat Al-Zahra, Madrid, Plus-Ultra, 1952.

USSHER, Arland, Spanish mercy, Londres, Victor Gollancz Ltd., 1959.

VALLEJO TRIANO, Antonio, "Problemas de gestión y administración de Madinat al-Zahra desde el inicio de su recuperación”, Arqueología y territorio medieval, vol. 1, 1994, págs. 17-29.

VALLEJO TRIANO, Antonio, La ciudad califal de Madinat al-Zahrä: arqueología de su excavación, Córdoba, Almuzara, 2010.

VALLEJO TRIANO, Antonio, "Madinat al-Zahra: realidad histórica y presente patrimonial”, Awraq: Estudios sobre el mundo árabe e islámico contemporáneo, n. ${ }^{\circ}$ 7, 2013, págs. 121-142. 